International Journal on Soft Computing (IJSC) Vol.3, No.3, August 2012

\title{
Performance Based Comparison Between Various Z-N Tuninng PID And Fuzzy Logic PID Controller In Position Control System Of Dc Motor
}

\author{
G.SUDHA ${ }^{1}$ \\ Assistant Professor / Electronics \& Instrumentation Engineering Department \\ Vivekanandha College of Technology for Women, Tiruchengode. \\ E Mail: kavisudhamariyaa@gmail.com \\ DR.R.ANITA ${ }^{2}$ \\ Professor\& Head, Electrical \& Electronics Engineering Department \\ IRTT, Erode. \\ E Mail: anitha_irtt@yahoo.co.in
}

\begin{abstract}
The objective of this paper is to compare the time specification performance between conventional controller and Fuzzy Logic controller in position control system of a DC motor. The scope of this research is to apply direct control technique in position control system. Two types of controller namely PID and fuzzy logic PID controller will be used to control the output response. This paper was written to reflect on the work done on the implementation of a fuzzy logic PID controller. The fuzzy controller was used to control the position of a motor which can be considered for a general basis in any project design containing logic control. Motor parameters were taken from a datasheet with respect to a real motor and a simulated model was developed using Matlab Simulink Toolbox. The fuzzy control was also designed using the Fuzzy Control Toolbox provided within Matlab, with each rule consisting of fuzzy sets conditioned to provide appropriate response times with regards to the limitations of our chosen motor. The Fuzzy Inference Engine chosen for our control was the Mamdani Minimum Inference engine. The results of the control provided response times suitable for our application.
\end{abstract}

\section{Key words:}

PID, fuzzy logic, position control system, DC motor, Z-N method

\section{Introduction}

DC motors are widely used in industrial applications, robotics and domestic appliances. PID controllers are commonly used for control applications. Controller parameters are generally tuned using hand-tuning or Ziegler-Nichols frequency response method. Both of these methods give successful results but long time and effort are required to obtain a satisfactory system response.

DOI: $10.5121 /$ ijsc.2012.3305 
International Journal on Soft Computing (IJSC) Vol.3, No.3, August 2012

Two main problems encountered in motor control are the time-varying nature of motor under operating conditions and existence of noise. Fuzzy set theory (Zadeh, 1965) leds to a new control called Fuzzy Control which is able to cope with system uncertainties. One of the most important advantages of fuzzy control is that it can be successfully applied to control nonlinear complex (Assilian, 1974), (Kickert, 1976).

Many papers deals with DC motor fuzzy control system design. Lin et. al. compared PID with FLC for position control and observed that FLC shows better performance than with PID (Lin, 1994). Azevedo et. al. have shown that FLC is less sensitive than PID to load variations (Azevedo, 1993). Mishra et. al. made a comparison between conventional PID and FLC for servomotor control against under variations of plant parameters (Mishra, 1998). Kwon et. al. designed a PI controller for a brushless DC motor and an adaptive fuzzy tuning system to modify the controller parameters under load variations during operation (Kwon, 2003). M.H. Zadeh et. al. explained that one of the best methods of a DC motor controller with time-varying parameters was fuzzy sliding mode control (Zadeh, 2006). Namazov et. al. designed a relay type fuzzy controller which is to be used for modelling many mechanical, hydraulic and electrical objects (Namazov, 2007). DC motor control is generally realized by adjusting the terminal voltage applied to the armature, inserting a resistor in series with the armature circuit is also available (Chapman, 2005).

Ziegler-Nichols tuning methods are usually used to adjust the parameters of the $\mathrm{P}+\mathrm{I}+\mathrm{D}$ controllers. However, it is needed to get the system into the oscillation mode to realize the tuning procedure. But not always possible to tune most of the plants into oscillation. The proposed approach uses both fuzzy controllers and Ziegler-Nichols tuning method to obtain the approximate values of the controller parameters. The parameters can be slightly varied to obtain the desired performance of control system. Thus, it's an actual problem to design PID controllers without getting the system into the oscillation mode.

\section{MATHEMATICAL MODELLING OF A DC MOTOR}

For reference we consider a DC motors as is shown in figure 1.

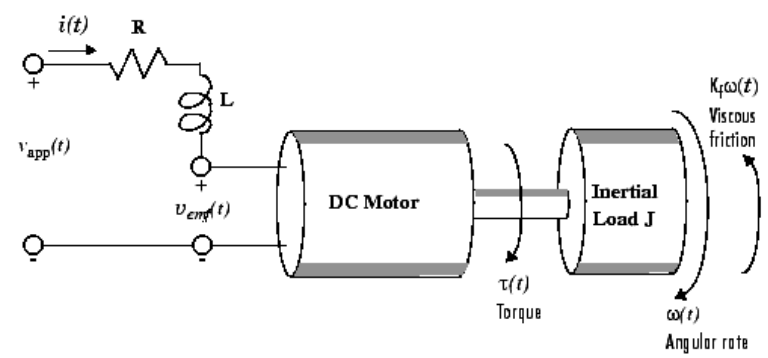

Fig 1. DC motor model

$$
v=R i+L \frac{d i}{d t}+e_{b}
$$




$$
\begin{aligned}
& T_{m}=K_{T} i_{a}(t) \\
& T_{m}=J \frac{d^{2} \theta(t)}{d t^{2}}+B \frac{d \theta(t)}{d t} \\
& \mathrm{eb}=e_{b}(t)=K_{b} \frac{d \theta(t)}{d t}
\end{aligned}
$$

Simplification and taking the ratio of $\theta(\mathrm{s}) / \mathrm{v}(\mathrm{s})$ we will get the transfer function as below,

$\Theta(s) / v(s)=K_{b} /\left[J L_{a} S^{3}+(R a \cdot+B I a) S^{2}+\left(K_{b}^{2}+R a B\right) S\right](S)$

Where, $\mathrm{R}=\mathrm{Ra}=$ Armature resistance in ohm,

$\mathrm{L}=\mathrm{La}=$ Armature inductance in henry, $\mathrm{i}=\mathrm{i} a=$ Armature current in ampere ,

$\mathrm{v}=\mathrm{Va}=$ Armature voltage in volts,

$\mathrm{eb}=\mathrm{e}(\mathrm{t})=$ Back emf voltage in volts,

$\mathrm{Kb}=$ back emf constant in volt/ $(\mathrm{rad} / \mathrm{sec})$,

$\mathrm{K}=\mathrm{Kt}=$ torque constant in $\mathrm{N}$-m/Ampere,

$\mathrm{Tm}=$ torque developed by the motor in $\mathrm{N}-\mathrm{m}$,

$\theta(t)=$ angular displacement of shaft in radians,

$\mathrm{J}=$ moment of inertia of motor and load in $\mathrm{Kg}-\mathrm{m} 2 / \mathrm{rad}$,

$\mathrm{B}=$ frictional constant of motor and load in $\mathrm{N}-\mathrm{m} /(\mathrm{rad} / \mathrm{sec})$

\section{A. Numerical Values}

The DC motor under study has the following specifications and parameters

a) Specifications

5hp, 230 volts, 10 amperes, $1500 \mathrm{rpm}$

b) Parameters:

$\mathrm{Ra}=2.45 \mathrm{ohm}, \mathrm{La}=0.035 \mathrm{H}, \mathrm{Kb}=1.2 \mathrm{volt} /(\mathrm{rad} / \mathrm{sec}), \mathrm{J}=0.022 \mathrm{Kg}-\mathrm{m} 2 / \mathrm{rad}, \mathrm{B}=0.5^{*} 10^{\wedge}-3 \mathrm{~N} \mathrm{~m} /$ $(\mathrm{rad} / \mathrm{sec})$.

The overall transfer function of the system is given below,

$$
\frac{\theta(\mathrm{s})}{\mathrm{v}(\mathrm{s})}=\frac{1.28}{0.00013919 \mathrm{~s}^{3}+0.0000007648 \mathrm{~s}^{2}+0.0002468 \mathrm{~s}}
$$




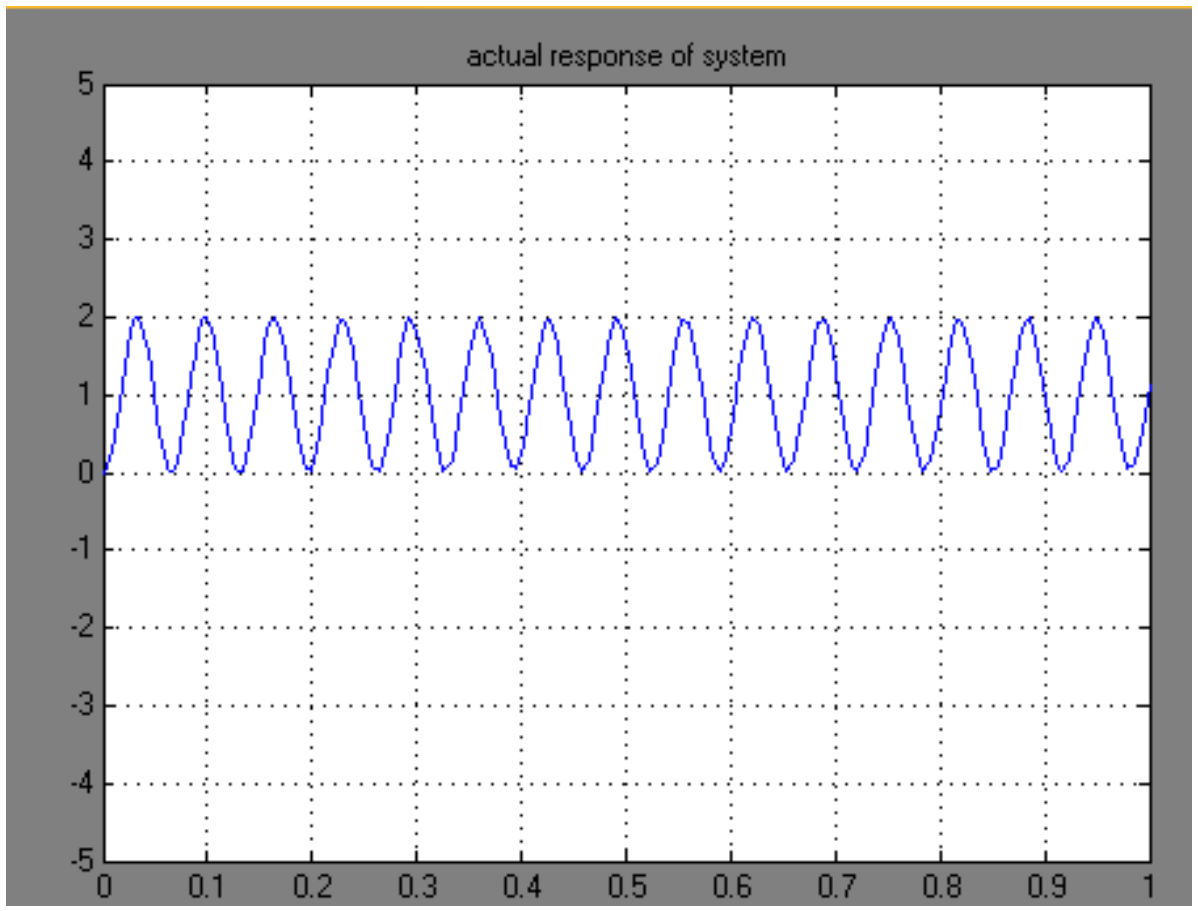

Fig 2. Response of original system without controller

\section{PID Controller}

PID stands for Proportional-Integral-Derivative. Each element of the PID controller refers to a particular action taken on the error. This section reviews the fundamental of PID controllers and presents detailed simulations or design for development of DC motor controller. PID controllers are commonly in the time-domain behavior of dynamic systems. They are extremely popular because the controller provides good response characteristics, which can be tuned using simple rules and are easy to construct.

Electric motor converts electrical energy into the mechanical motion and are broadly classified into two different categories: DC (Direct Current) motor and AC (Alternating Current) motor. DC motors are usually modeled as linear systems where linear control approaches are implemented. Most of the linear controllers give unsatisfactory performance due to the load changes of motor and due to the nonlinearities of armature reaction. The impact of external disturbances and of nonlinearities may risk the stability of the closed loop system. For this reason, the DC motor control using the conventional PID controller is inadequate and more effective. Here, the test system with conventional PID controller tuned by Ziegler Nichols method is compared with Fuzzy based PID controller. The results with Fuzzy based PID controller has been found to outperform the Ziegler Nichols tuned PID controllers.

\subsection{Tuning and Its Purpose}

A PID may have to be tuned when 
International Journal on Soft Computing (IJSC) Vol.3, No.3, August 2012

a) Consideration should not be given to the units of gains and other parameters.

b) The process dynamics were not Well-understood when the gains or the dynamics have changed.

c) Some characteristics of the control system are direction-dependent

d) The operator should think the controllers can perform better.

\subsubsection{Trial and error method}

This process is time consuming process. Though much iteration is performed the final result will not be satisfactory. A balance is not obtained between the rise time and \% overshoot even though a lot of possible combinations of the gains are incorporated. Continuous cycling may be objectionable because the process may reach to the stability limit. Consequently, if external disturbances or a change in the process occurs during controller tuning, it results to the unstable condition. The tuning process is not applicable to processes that are open loop unstable at high and low values of $\mathrm{K}_{\mathrm{c}}$ but are stable at intermediate range of values. All the time response specifications cannot be balanced using trial and error method.

\subsubsection{Ziegler Nichols method}

Ziegler Nichols formula gives good load disturbance attenuation, but it generally provides a poor phase margin and therefore it produces a large overshoot and settling time in the step-response. The Ziegler-Nichols rule is a heuristic PID tuning rule that attempts to produce good values for the three PID gain parameters:

1.

2.

constant

3.

constant
$K p$ - the controller path gain

$\mathrm{Ti}$ - the controller's integrator time

$T d$ - the controller's derivative time

Given two measured feedback loop parameters derived from measurements:

1. the period $T u$ of the oscillation frequency at the stability limit

2. the gain margin $K u$ for loop stability for disturbance rejection).

\subsection{2. a. Ziegler-Nichols Open-Loop Point of Inflection (POI) PID Tuning Method}

The Ziegler Nichols Open-Loop Point of Inflection (POI) PID Tuning Method is nearly identical to the "Reaction Curve" Method. The open loop step change was conducted in the same manner under the same conditions as in the reaction curve method. The only difference is in the determination of the delay factor, D. Instead of determining the D value as in Fig.3, the following values are acquired from the graphical analysis: 
International Journal on Soft Computing (IJSC) Vol.3, No.3, August 2012

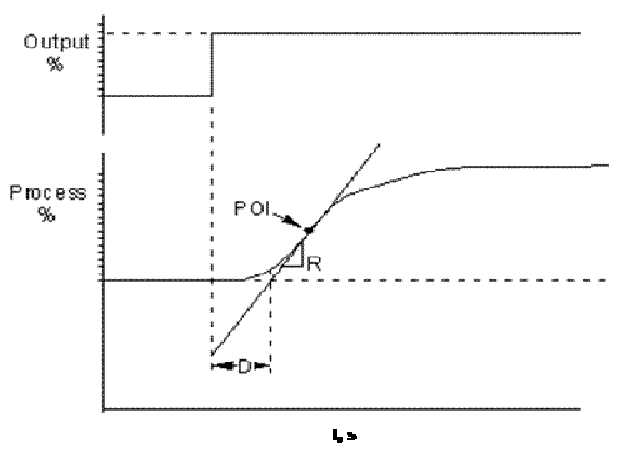

Fig. 3 Graphical analysis for Ziegler Nichols Open-Loop Reaction Rate PID Tuning Method

Where:

tPOI, is the time from the initiated change in output to the point of inflection, $s \Delta C V P O I$,is the controlled variable change at POI, $\% \mathrm{R}$, is the rate of change of controlled variable at POI (same as Reaction Curve Method), \%/s $\Delta \mathrm{MV}$, is the change of output (manipulated variable), $\%$ and then

$$
\mathrm{D}=\mathrm{t}_{\mathrm{POI}}-\Delta \mathrm{CV}_{\mathrm{POI}} / \mathrm{R}
$$

Parameters for P, PI, and full PID control are then calculated using the same formulae as in the ZN Reaction Curve Method.

\begin{tabular}{|l|l|l|l|}
\hline controllers & $\mathbf{K}_{\mathbf{C}}$ & $\mathbf{T}_{\mathbf{I}}$ & $\mathbf{T}_{\mathbf{D}}$ \\
\hline $\mathbf{P}$ & $\Delta \mathrm{MV} /(\mathrm{D} \times \mathrm{R})$ & - & - \\
\hline $\mathbf{P I}$ & $0.9 \Delta \mathrm{MV} /(\mathrm{D} \times \mathrm{R})$ & $3.3 \mathrm{D}$ & - \\
\hline $\mathbf{P I D}$ & $1.2 \Delta \mathrm{MV} /(\mathrm{D} \times \mathrm{R})$ & $2.0 \mathrm{D}$ & $0.5 \mathrm{D}$ \\
\hline
\end{tabular}

Table 1. Calculation of PID Parameters based on Ziegler Nichols Open-Loop Point of Inflection PID Tuning Method 


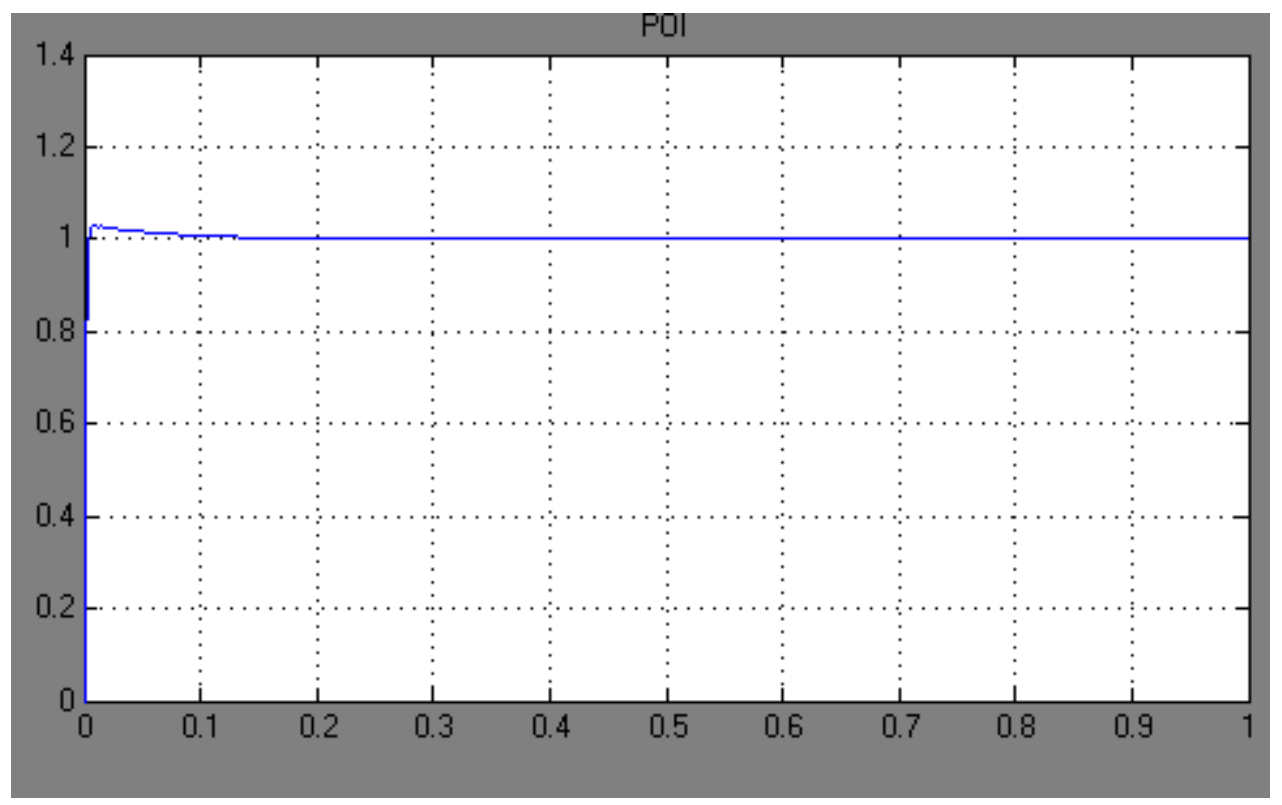

Fig 4. Response of the system with tuning based on POI method

\subsection{2. b. Tuning based on stability margins}

Ziegler-Nichols closed loop tuning is based on the method of stability margins. To identify process

Parameters:

1. Turn off both integral and derivative action in the controller.

2. Set the proportional gain $(\mathrm{Kc})$ to a small value.

3. Put the controller in Auto mode.

4. A small step in the controller setpoint.

5. Observe the process response.

6. If the controller does not continually cycle (stability limit), increase the controller gain $(\mathrm{Kc})$ and repeat from step 4.

7. Once the controller continually oscillates, the controller gain is termed as ultimate gain Kcu.

8. The period of the cycle measurement is termed as ultimate period $\mathrm{Pu}$.

\begin{tabular}{|c|c|c|c|}
\hline \multicolumn{4}{|c|}{ Ziegler-Nichols Stability Margin } \\
\hline Controller Type & $\mathrm{K}_{\mathrm{c}}$ & $\tau_{\mathrm{I}}$ & $\tau_{\mathrm{D}}$ \\
\hline $\mathrm{P}$ & $0.5 \mathrm{~K}_{\mathrm{cu}}$ & - & - \\
\hline $\mathrm{PI}$ & $0.45 \mathrm{~K}_{\mathrm{cu}}$ & $\frac{P_{u}}{1.2}$ & - \\
\hline $\mathrm{PID}$ & $0.6 \mathrm{~K}_{\mathrm{cu}}$ & $\frac{P_{u}}{2.0}$ & $\frac{P_{u}}{8.0}$ \\
\hline
\end{tabular}

Table 2. Calculation of PID Parameters based on Ziegler Nichols Stability Margin Tuning Method 


\section{$\mathrm{K}_{\mathrm{cu}}=$ Ultimate gain (Minimum gain with P-only control that causes system to cycle continuously) \\ $\mathrm{P}_{\mathrm{u}}=$ Ultimate period of oscillation}

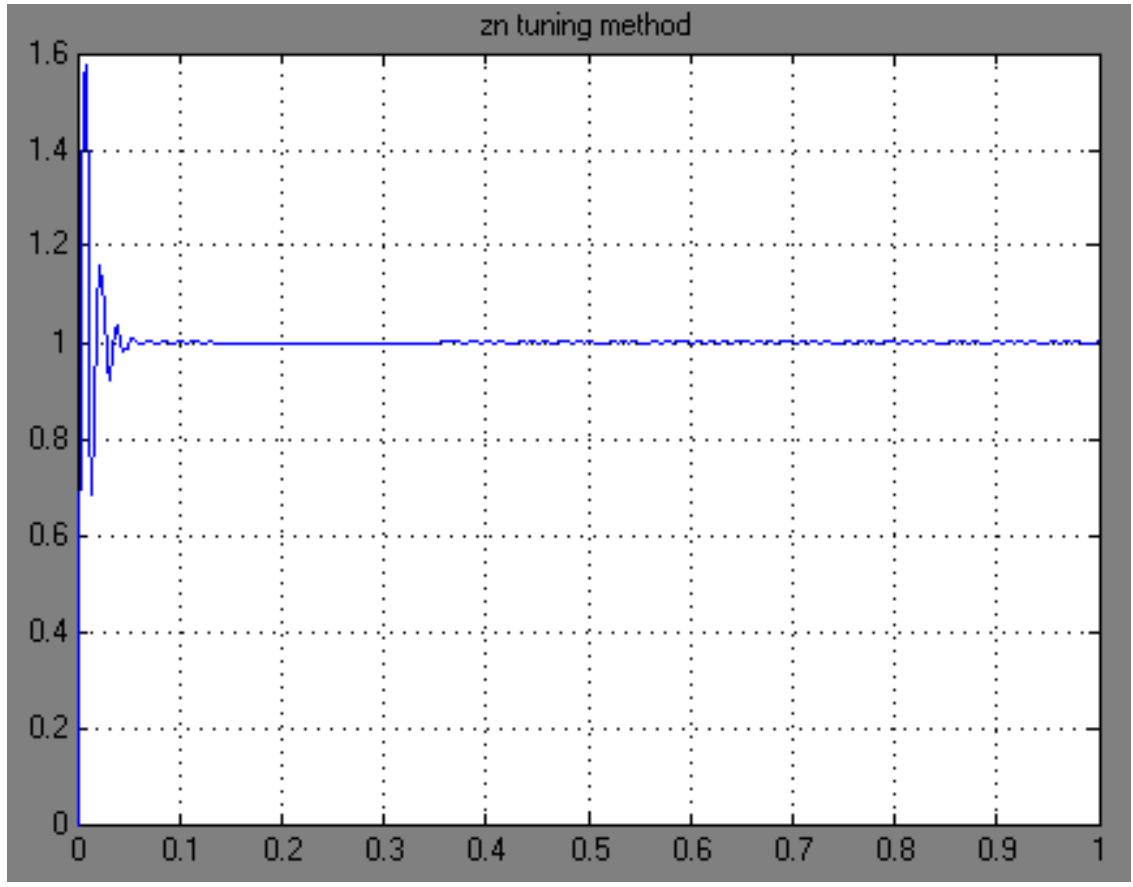

Fig 5. Response of the system with tuning based on stability margin

\subsection{FUZZY LOGIC}

\section{A. Introduction}

Fuzzy logic is a derivative from classical Boolean logic and implements soft linguistic on a continuous range of truth values to be defined between conventional binary. It can often be considered a suspect of conventional set theory. Since fuzzy logic handles approximate information in a systematic manner, it is ideal for controlling non-liner systems and fro modeling complex systems where an inexact model exists or systems where ambiguity or vagueness is common. A typical fuzzy system consists of a rule base, membership functions and an inference procedure [9]. Today, fuzzy logic are found in a variety of control applications like chemical process control, manufacturing and in such consumer products as washing machines, video cameras and automobiles. Fuzzy logic is a suspect of conventional Boolean logic that has been extended to handle the concept of partial truth- truth- values between "completely true" and "completely false".Fuzzy theory as a single theory, we should regard the process of fuzzification as a methodology to generalize ANY specific theory from a crisp (discrete) to a fuzzy (continuous) form. Thus, recently, researchers have also introduced "fuzzy calculus" and "fuzzy differential equations" 


\section{B. Fuzzy Rule Base}

Fuzzy logic has been centered on the point that it makes use of linguistic variables as its rule base. If a variable can take words in natural language as its values, it is called linguistic variable, where the words are characterized by fuzzy sets defined in the universe of discourse in which the variable is defined. Examples of these linguistic variables are slow, medium, high, young and thin. There could be combinations of this variable too, like "slow-young horse", "a thin young female." These characteristics are termed atomic terms while their combinations are called compounded terms. In the real world, words are often used to describe characteristics rather than numerical values. For example, one would say "the car was going at 100 miles per hour." Terms such as slightly, very, more or less, etc. are called linguistic hedges since they add extra description to the variables, i.e. very - slow, more or less, slightly high, etc. At the heart of the fuzzy rule base are the IF-THEN rules.

A fuzzy IF-THEN rule is expressed as,

IF $<$ fuzzy proposition $>$,

THEN $<$ fuzzy proposition $>$.

Propositions are linguistic variables or atomic terms as described previously. This type of rulebased system is different from the classical expert systems, In that, rules may not necessarily be derived from human expertise; they may also be derived from other sources. Three types of linguistic variable forms exist.

1. Assignment statements

2. Conditional statements

3. Unconditional statements

\section{Fuzzy Logic Controller Design}

The traditional control design paradigm is to form a system model and develop control laws. The controller may be modified based on results of testing and experience. Due to difficulties of analysis, many such controllers are linear. The fuzzy controller approach should be reversed to some extent. General control rules will be based on experience are introduced and analyzed. Implementation of this concept is for anticipating the position and reducing the control level to avoid overshoot.

The quantities like "small" and "large" are used in fuzzy quantities. A controller design requires a set of control rules based on the inputs. The precise fuzzy membership functions depend on the wide range of inputs and the general response characteristics of the system. Within power systems, fuzzy logic controllers primarily using MATLAB - FIS Editor have been proposed

The structure of the Fuzzy Logic Controller (FLC) and its design consist of the following steps

1) Identification of input and output variables.

2) Construction of control rules.

3) Establishing the approach for describing system state in terms of fuzzy sets, i.e., establishing fuzzification method and fuzzy membership functions. 
4) Selection of the compositional rule of the inference.

\subsection{Membership Functions}

The membership functions consist of the seven linguistic terms:

* Negative Large Large (NLL)

* Negative Large (NL)

* Negative Small (NS)

* Zero $(\mathrm{Z})$

* Positive Small (PS)

* Positive Large (PL)

* Positive Large Large (PLL)

The input e presented in Figure 6 consists of all seven terms to increase response with respect to the error. The input ce and output cu both have five terms as shown in Figures 7 and 8 since it was optimal to keep them at a lower degree of precision. All membership functions were chosen to be of the triangular and trapezoidal type, mostly due to its common use during class and straightforward implementation.

\subsection{Fuzzy Rule Base}

The input e uses seven membership functions, while ce uses five, which required a rule base consisting of 35 rules. The resulting rule base can be seen in Table 2.

The rule base was developed to present smooth, gradual transitions to an error relative to zero error by attempting to decrease the change in error, ce.

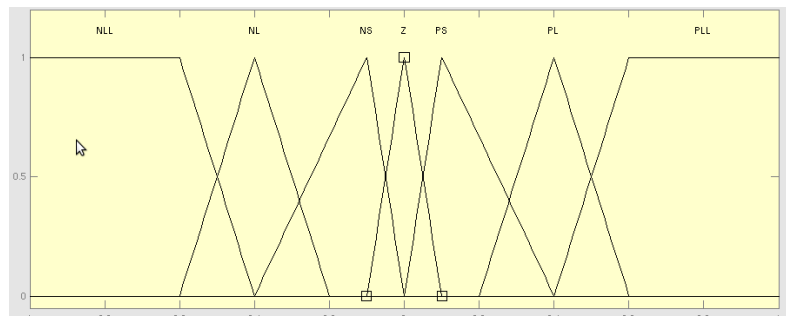

Fig 6. Membership function for e, $\mu \mathrm{e}(\mathrm{x} 1)$

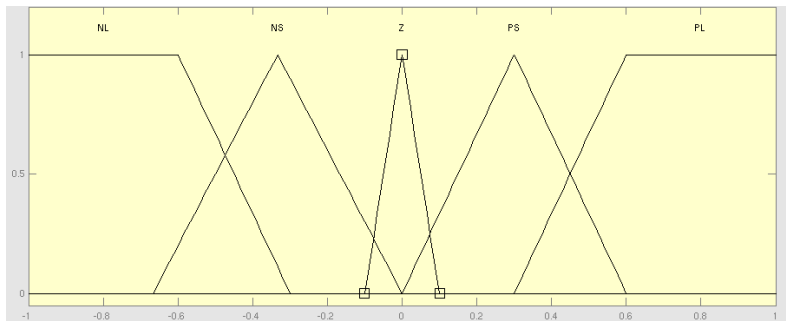

Fig 7. Membership function for ce, $\mu$ ce(x2) 
International Journal on Soft Computing (IJSC) Vol.3, No.3, August 2012

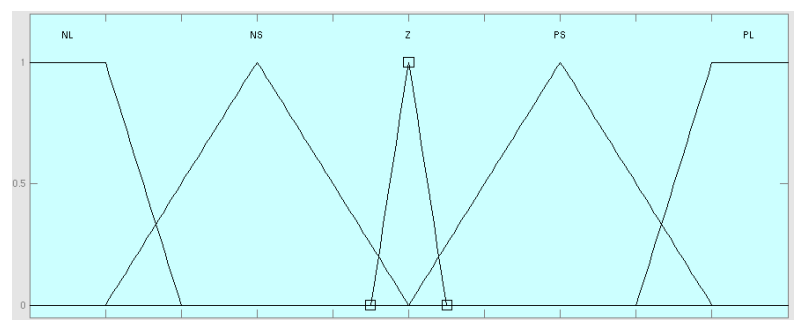

Fig 8. Membership function for $\mathrm{cu}, \mu \mathrm{cu}(\mathrm{y})$

\begin{tabular}{|l|l|l|l|l|l|}
\hline Ce $/ \mathrm{e}$ & NL & NS & Z & PS & PL \\
\hline NLL & NL & NL & NL & NS & NS \\
\hline NL & NL & NL & NS & NS & Z \\
\hline NS & NL & NS & NS & Z & Z \\
\hline Z & NS & Z & Z & Z & PS \\
\hline PS & Z & Z & PS & PS & PL \\
\hline PL & Z & PS & PS & PL & PL \\
\hline PLL & PS & PS & PL & PL & PL \\
\hline
\end{tabular}

Table 3: Membership Rule Base

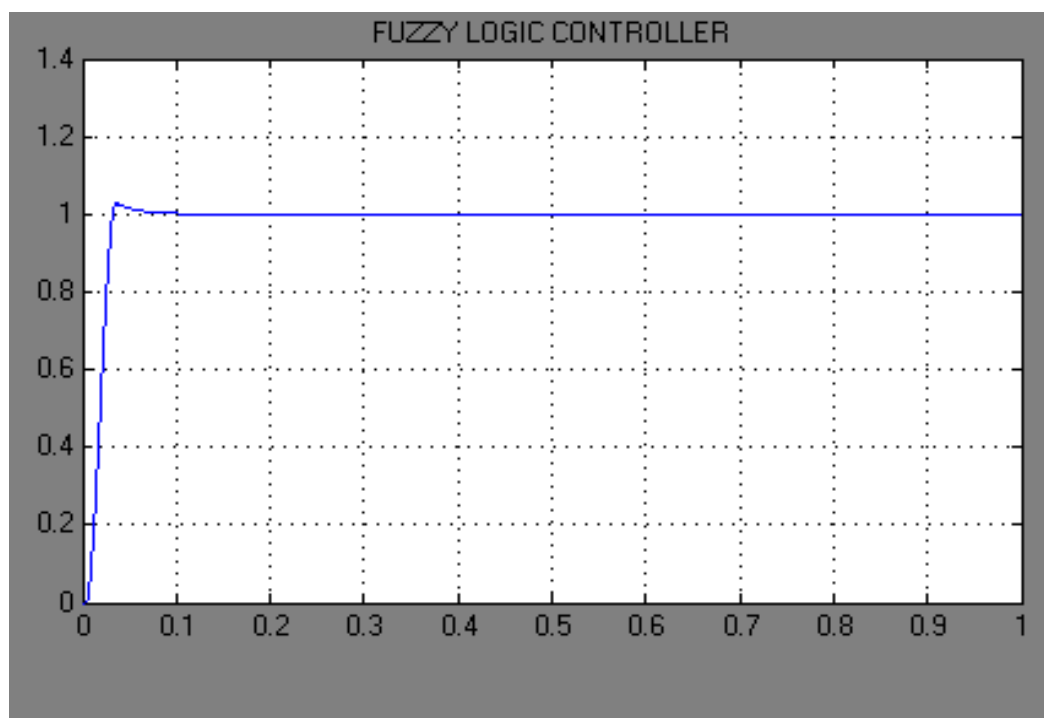

Fig 9. Response of the system based on the fuzzy logic controller 


\section{Performance Analysis}

The most desirable performance requires the Controllers to have the smallest possible value for the rise time, overshoot and the settling time. It is also required for the final value should be as close as possible to the desired value which is unity. From the table, it can be seen that the fuzzy logic controller can produce a desirable response performance with the use of only the proportional, Integral and Derivative Component (PID). When compared to the conventional PID controller, the fuzzy logic PID controller shows a better performance in terms of raise time while it exhibits a slightly lesser performance in terms of peak value and settling time.

\begin{tabular}{|l|c|c|c|}
\hline \multirow{2}{*}{ Performance metric } & \multicolumn{3}{|l|}{ With controller (various PID tuning) } \\
\cline { 2 - 4 } & ZN-POI & ZN-SM & FLC \\
\hline Raise time & 0.017 & 0.0245 & 0.0218 \\
\hline Settling time & 0.29 & 1.00 & 0.155 \\
\hline Peak value & 1.0301 & 1.5765 & 1.025 \\
\hline Final value & 1.000 & 1.000 & 0.9985 \\
\hline Over shoot & 0.030 & 0.576 & 0.025 \\
\hline
\end{tabular}

\section{CONCLUSION}

The designed PID with Fuzzy based has much faster response than response of the classical method. However the Fuzzy logic designed PID is much better in terms of the peak value and the settling time than the conventional method. Finally the fuzzy based PID controller provides much better results compared to the conventional methods. In this paper, implementation of the fuzzy based PID controller for the DC motor position control system is covered.

\section{REFERENCES}

[1] I.J.Nagrath and M.Gopal. 1999 Control systems engineering.

[2] O. Dwyer,.PI And PID Controller Tuning Rules For Time Delay Process: A Summary. Part 1: PI Controller Tuning Rules.., Proceedings Of Irish Signals And Systems Conference, June 1999.

[3] O. Montiel, R. Sepúlveda, P. Melin and O. Castillo, "Performance of a simple tuned Fuzzy controller and a PID controller on a DC motor,” Procee. of IEEE (FOCI 2007), pp. 531-538, 2007.

[4] G. Haung and S. Lee, "PC based PID speed control in DC motor," IEEE Conf. SALIP-2008, pp. 400408, 2008.

[5] Khongkoom N.,Kanchanathep A.,Nopnakeepong S., Tanuthong S.,Tunyasrirut S.,Kagawa R., “Control of the position DC servo motor by fuzzy logic," TENCON 2000. Proceedings , 2000,3 ,pp. 354-357

[6] Tang K.S., Kim Fung Man, Guanrong Chen, Kwong S., “An optimal fuzzy PID controller,” Industrial Electronics, IEEE Transactions on , 2001, 48, pp. 757 - 765 
International Journal on Soft Computing (IJSC) Vol.3, No.3, August 2012

[7] K.J.Aström,T. Hägglund,C.C. Hang,and W. K. Ho, "Automatic tuning and adaptation for PID controllers-A survey,"in Adaptive Systems in Control and Signal Processing, L. Dugard, M. M'Saad, and I.D.Landau,Eds. Oxford,U.K.: Pergamon,2006, pp.371-376.

[8] Timothy J.Rose, 1997 "Fuzzy Logic with Engineering Applications", Mc - GrawHill.Inc, New York

[9] Zadeh, M. H., Yazdian, A. and Mohamadian, M., Robust Position Control in DC Motor by Fuzzy Sliding Mode Control. International Symposium on Power Electronics, Electrical Drives, Automation and Motion (SPEEDAM 2006), 1413-1418, 2006.

[10] Arpit Goel, Ankit Uniyal, Anurag Bahuguna, Rituraj S. Patwal and Husain Ahmed "Performance Comparison Of PID And Fuzzy Logic Controller Using Different Defuzzification Techniques For Positioning Control Of DC Motors" Journal of Information Systems and Communication ISSN: 09768742 \& E-ISSN: 0976-8750, Volume 3, Issue 1, 2012, pp.-235-238.

[11] G. Haung and S. Lee, "PC based PID speed control in DC motor," IEEE Conf. SALIP-2008, pp. 400408, 2008.

\section{Authors}

G.SUDHA was born in India. She received her B.E. degree in Electronics and Instrumentation Engineering from Maharaja Engineering College, Avinashi and the M.E degree in Process Control and Instrumentation from Annamalai University, Chidambaram in India. Currently, she is working as Assistant Professor, Department of Electronics and Instrumentation Engineering in Vivekanandha College of Technology for Women, Tiruchengode, India. Her research interests include control system and artificial intelligence techniques applications, Process Control.

Dr. R. Anita was born in India. She received her B.E. degree in Electrical and Electronics Engineering from Government College Technology, Coimbatore and the M.E degree in Applied Electronics from Coimbatore Institute of Technology, Coimbatore in India and the Ph.D. degree from the Anna University, Chennai, India in 2004. Currently, she is working as a Professor \& Head, Department of Electrical and Electronics Engineering in Institute of Road and Transport Technology, Erode, India 638316 . At present she is guiding more than 15 research scholars. One of them has been awarded Ph.D. She has published 52 papers. Her research interests include condition

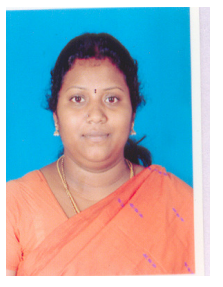
monitoring of power apparatus and systems, insulation engineering, control system and artificial intelligence techniques applications in electric power engineering.

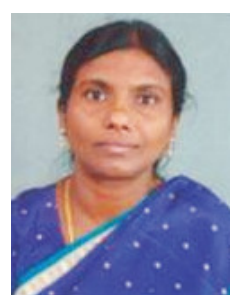

